\title{
DÜBLIN
}

Technological University Dublin ARROW@TU Dublin

2009-01-01

\section{Double-Glazing Interferometry}

Vincent Toal

Technological University Dublin, vincent.toal@tudublin.ie

Emilia Mihaylova

Technological University Dublin, emilia.mihaylova@tudublin.ie

Follow this and additional works at: https://arrow.tudublin.ie/scschphyart

Part of the Physics Commons

\section{Recommended Citation}

Toal, V. \& Mihaylova, E. (2009) Double-glazing Interferometry. Physics Teacher, Vol.47, no. 5, pp.295-296. doi:10.1119/1.3116841

This Article is brought to you for free and open access by the School of Physics \& Clinical \& Optometric Science at ARROW@TU Dublin. It has been accepted for inclusion in Articles by an authorized administrator of ARROW@TU Dublin. For more information, please contact arrow.admin@tudublin.ie, aisling.coyne@tudublin.ie, gerard.connolly@tudublin.ie.

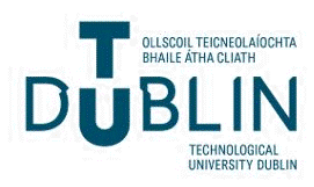




\section{Double-Glazing Interferometry}

Vincent Toal and Emilia M. Mihaylova, Centre for Industrial and Engineering Optics,

Dublin Institute of Technology, Dublin 8, Ireland

$\mathbf{T}$ his note describes how white light interference fringes can be seen by observing the Moon through a double-glazed window. White light interferometric fringes are normally observed only in a well-aligned interferometer whose optical path difference is less than the coherence length of the light source, which is approximately one micrometer for white light. Obtaining such fringes in a Michelson interferometer is not a trivial task. ${ }^{1}$ The interferometer is typically illuminated with a monochromatic source and the path length difference adjusted with a wedge angle between the interferometer mirrors so that five or six vertical fringes are visible, indicating nearly equal paths. Then the mirrors are adjusted until the fringes are almost perfectly straight. Finally we use a white light source and carefully scan through the approximately equal path range until five or six white light fringes are seen to sweep rapidly by.

\section{Observation of Interference Fringes in Double-Glazed Windows}

Ferguson ${ }^{2}$ provides a very detailed analysis of the phenomenon of fringe formation in double-glazed windows. Also considered are the effects of a wedge angle between the panes and it is shown that interference fringes may be observed, even with panes of unequal thickness. The analysis assumes that the light source, effectively the spacer, is between the panes.

Another way to observe interference fringes through a double-glazed window is to look at an external light source and observe the rather faint secondary image. Figure 1 shows how the interference effect

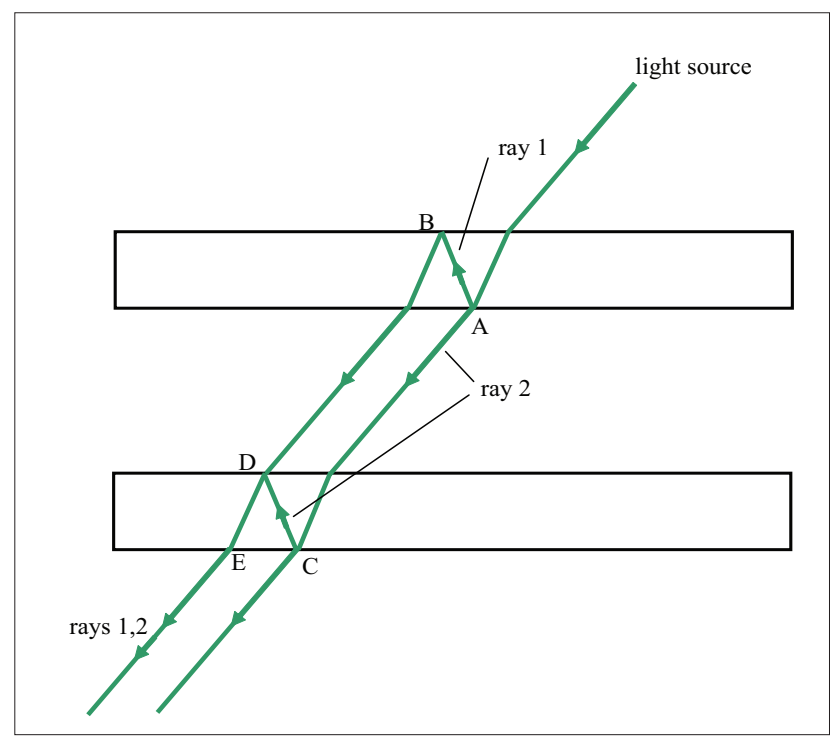

Fig. 1. Ray paths through a double-glazed window showing how interference occurs in the secondary image.

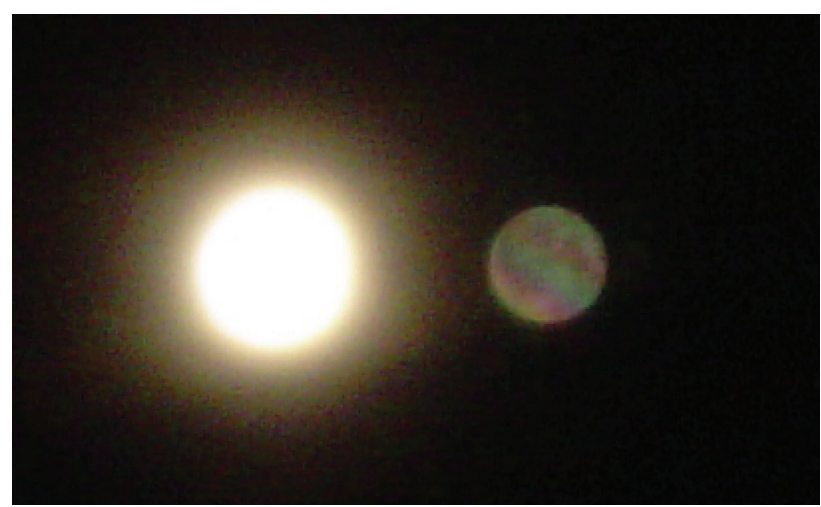

Fig 2. Full Moon photographed through double-glazed window. The secondary image on the right shows the white light interference fringes. 
arises in a contemporary double-glazed unit whose panes are of very uniform, equal thickness, have the same refractive indices and chromatic dispersions, and are set parallel to each other.

A division of amplitude occurs at a point $A$ on the inner face of the outer pane. Ray 1 is internally reflected at the outer face (B) and then transmitted through the two panes as shown, with some loss at each boundary. Ray 2 is partially reflected at $\mathrm{C}$ and recombines with ray 1 at $D$. The intensities of the two light beams emerging at point $\mathrm{E}$ are both very low, but approximately equal so that the contrast of any fringes that are seen is likely to be quite high. As pointed out in Reference 2, the fringes are not easy to see against a bright background, as is the case when one attempts to view extended sources such as skylight. However, interference fringes can be observed fairly easily from other sources, such as a sodium street lamp or the Moon, which subtend small angles at the observer. The longer coherence length of sodium lamps means that the monochromatic interference fringes are quite easily seen.

Observation of white light fringes, with the Moon as the source, is more difficult, but, with a little perseverance, they can be seen. In practice it may be necessary to change the observation point to ensure favorable conditions. By moving one's viewpoint slightly from side to side, a series of faint, colored fringes is observed to move across the Moon's disc in the secondary image. Figure 1 shows that rays 1 and 2 have almost the same optical path length if the stated assumptions about the nature of the double-glazing unit are correct and that therefore any variation in the optical path difference is extremely small, arising only from differences in the optical thicknesses and dispersions of the glass panes and their lack of parallelism. In this way white light fringes are almost guaranteed.

A photograph of the full Moon, showing white light fringes in the secondary image, is shown in Fig. 2. Success is more likely when the Moon is low in the sky, or observation made from the window of a tall building, so that angle of incidence is not so large that the optical path difference exceeds the coherence length.

Although these observations have no practical application of which we are aware, they provide a simple and convincing demonstration of white light and monochromatic interference phenomena.

\section{References}

1. Eugene Hecht, Optics, 4th ed. (Addison-Wesley, San Francisco, CA, 2002), pp. 407-411.

2 Joe L. Ferguson, "Thermal window interferometer," Am. J. Phys. 50, 1021-1024 (Nov. 1982 ).

PACS codes: $01.55 .+b, 42.00 .00$

Vincent Toal is professor and Head of the School of Physics at Dublin Institute of Technology (DIT). His research interests are in holographic recording materials and their applications.

Dublin Institute of Technology, Kevin Street, Dublin 8, Ireland; vincent.toal@dit.ie

Emilia Mihaylova is associate professor of physics at the Agricultural University of Plovdiv, Bulgaria, where she specializes in teaching general physics. She is currently a visiting researcher at DIT. Her research work is in optics, with emphasis on interferometry and holography.

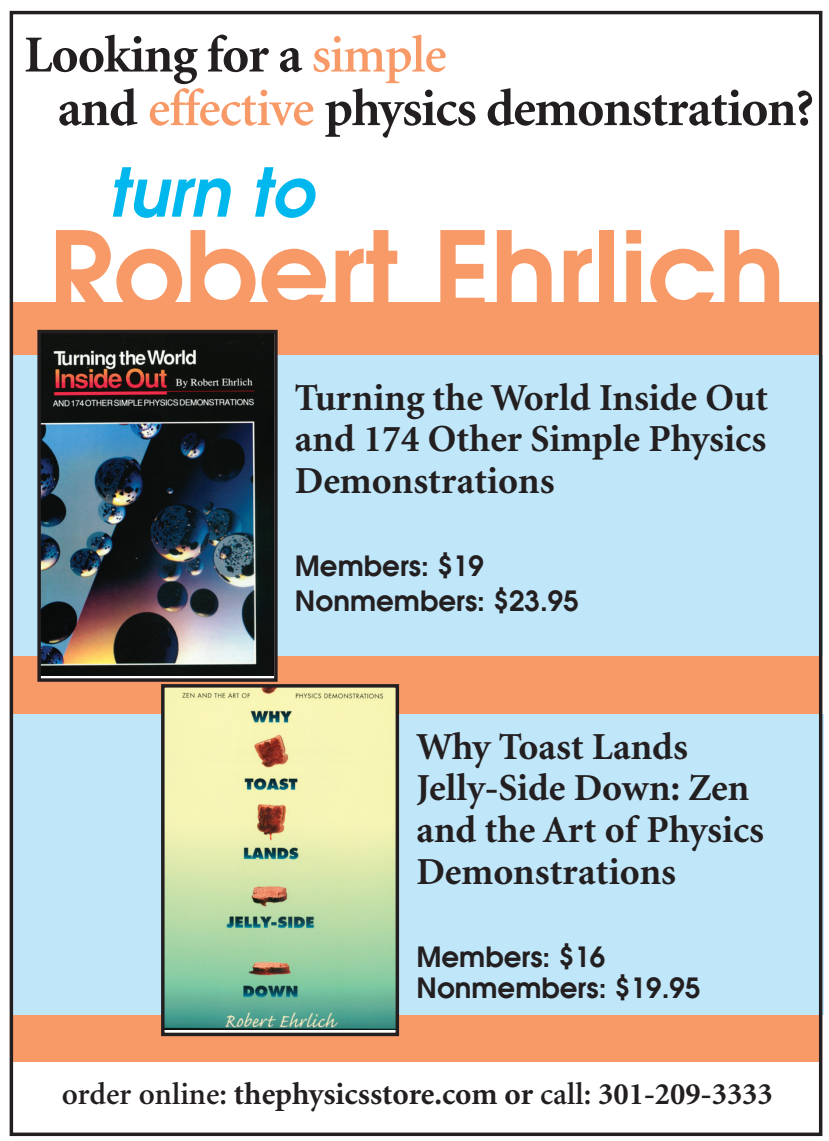

